\title{
Dimethacrylate based Composite Resins for Interim Restorations in Achievement Ceramic Veneers
}

\author{
CLAUDIA FLORINA ANDREESCU, DOINA LUCIA GHERGIC, ANDREEA MARIANA BANATEANU, ANAMARIA BECHIR*, \\ DAN NICOLAE PATROI, VIOLETA HANCU \\ Titu Maiorescu University of Bucharest, Faculty of Dentistry, Department of Dental Specialities, 67A Gheorghe Petrascu Str. , \\ 031593 Bucharest, Romania
}

\begin{abstract}
The aim of this study was to evaluate the interim veneer restoration, achieved from two types of dimethacrylate based composite resins (Telio CS C\&B and Luxatemp Star), by direct technique. Both composite resins performed well according to evaluation criteria: anatomic configuration, marginal adaptation, discoloration, surface texture, postoperative pain and periodontal aspect. Loosening of interim restorations appeared in $25 \%$ of cases. Besides advantages, there are some disadvantages associated with direct way of achieving temporary veneers.
\end{abstract}

Keywords: dimethacrylate resins, direct interim veneers

Resins represented a major step forward in dentistry, the first acrylic thermocured resins coming up in 1936 [1].

Continuous developmentand progress of the polymer's industry with application in general and dental medicine have their ground in the importance of these biomaterials in the health domain. Acrylic resins dominated dentures technology for several decades, being used for denture and removable orthodontic bases, artificial teeth, veneering materials, dental restorations [2].

Modern restorative dentistry focuses on the high-quality interim restorations, which serve as a model for the laboratory when are fabricated the final restorations. Requests of interim/temporary/provisional dental restorations are increased in lasts years due to development of implant and cosmetic dentistry [3].

The interim restoration requires good marginal adaptation, physiologic contours and embrasures, a smooth plaque-resistant surface [4], but also strength and durability [5].

According to Rosenstiel et al [6], the characteristics of an ideal interim material are the convenienthandling, their biocompatibility, the dimensional stability during solidification, ease of contouring and polishing, adequate strength and abrasion resistance, good appearance, translucent, controllable and stable colour, good acceptability of patient, chemical compatibility with interim luting agents.

A patient's temporaries are essential to creating the ideal veneer case in terms of identifying the proper look and feel of the final restorations, as well as to allow the patient to maintain their privacy and dignity by not letting anyone know they are undergo dental treatment [7].

In dentistry, a veneer is a layer of material placed over a tooth, either to improve the aesthetics of a tooth or to protect the tooth's surface from damage. Porcelain veneers are a very conservative approach to changing the shape, shade, and contour of teeth without resorting to a full coverage restoration [8].

Fabrication and retention of provisional restorations for veneer preparations present special challenges because preparation design for adhesively retained restorations offers little, if any, mechanical retention [9].

The material used for fabrication of interim restorations contains pigments, monomers, filler, and an initiator. The important characteristics of the interim restorative material are determined by the primary monomer. The most commonly used monomers are classified according to their chemistry in acrylic or methacrylate resins (methyl methacrylate, ethyl methacrylate, isobutyl methacrylate, vinyl methacrylates) and dimethacrylate composites or composite resins (Bis-GMA, Bis-acryl, urethane dimethacrylate), each one with advantages and disadvantages [10]. The chemical structure of BisGMA is presented figure 1[11].

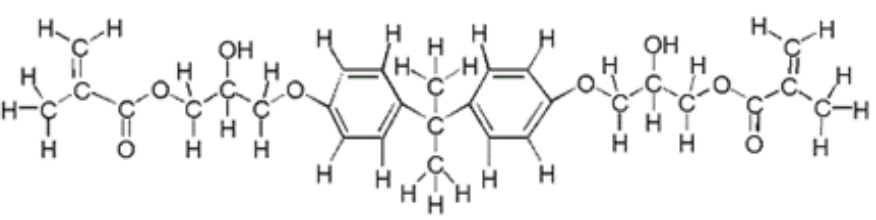

Fig. 1. Chemical structure of BisGMA

In this study, we used two dimethacrylate-based products. These were dispensed from a cartridge with a static mixing device, which help manipulation and ensure a homogeneously mixed material that contribute to superior flexural strength because of a more accurately proportioned and consistent mix [12].

Telio CS C\&B is a self-curing composite resin based on dimethacrylates product, used as temporary material for high-quality temporary crowns, bridge restorations, inlays, onlays, post-retained temporaries and veneers. It provides an accurate fit and allows stress-free restorations. In addition to the high stability, the material features low polymerization shrinkage and absorbs little water [13]

Telio CS C\&B is composed of polyfunctional methacrylates (48 wt \%) and inorganic fillers (47 wt \%) [14].

Standard Telio CS C\&B base is is pasty form, with the density at $20^{\circ} \mathrm{C}\left(68{ }^{\circ} \mathrm{F}\right): 1.55 \mathrm{~g} / \mathrm{cm}^{3}(12.935 \mathrm{lbs} / \mathrm{gal})$, and contain (in wt\%) dimethacrylates $51.1 \mathrm{~m}$ barium glass filler, highly dispersed silicon dioxide 48.7, initiators, stabilizers and pigments 0.2 [15]. Standard Telio CSC\&B catalysthave the density at $20^{\circ} \mathrm{C}\left(68{ }^{\circ} \mathrm{F}\right): 1.52 \mathrm{~g} / \mathrm{cm}^{3}$ (12.684 lbs/gal) [16] and contain (in wt\%) triglyceride 35.9, glass filler 57.0, initiators and stabilizers 7.1 [17]. Additional ingredients include additives, initiators, stabilizers and pigments (5 wt $\%)$. Of physical properties, Telio CS C\&B present the flexural strength between the values 85 - $95 \mathrm{MPa}$, the working time 
(at $23^{\circ} \mathrm{C}$ ) $65-80 \mathrm{~s}$, and the setting time (at $37^{\circ} \mathrm{C}$ ) $65-80$ seconds [14]. The material is dispensed from a cartridge with a static mixing device. Thus homogeneously mixed material is ensured, down to the last drop [17].

Luxatemp Star is a bis-acryl self-cured provisional material with excellent flexural strength and break resistance and improved initial hardness, cytocompatible with human gingival fibroblasts [18], less prone to discoloration in coffee, tea and blackcurrant juice in comparison with different temporary material [19].

Luxatemp Star present the compressive strength after $24 \mathrm{~h}$ of $376 \mathrm{MPa}$, the flexural strength after $24 \mathrm{~h}$ of $125 \mathrm{MPa}$ and the tensile strength after $24 \mathrm{~h}$ of $52 \mathrm{MPa}$ [20]. High volumetric shrinkage leads to shrinkage-induced stresses, which result in a weakening of the temporary material and accuracy of fit may be compromised. Telio CS has a volumetric shrinkage of $4 \%$ and Luxatemp less than $5 \%$. For Telio CS and Luxatemp the measured temperature during setting reaction increases of around $3^{\circ} \mathrm{C}$ is tolerable and do not increase the risk of tissue or pulp damage [21]. Telio CS has a flexural strength of $90 \mathrm{MPa}$ [26] and Luxatemp $125 \mathrm{MPa}$ [22].

The aim of this study is to evaluate the interim veneer restoration, achieved from two types of dimethacrylate based composite resins, by direct technique.

\section{Experimental part}

Material and method

In figure 2 are presented Luxatemp Star and Telio CS $\mathrm{C} \& \mathrm{~B}$ dimethacrylate based composite resin systems, used in this study.
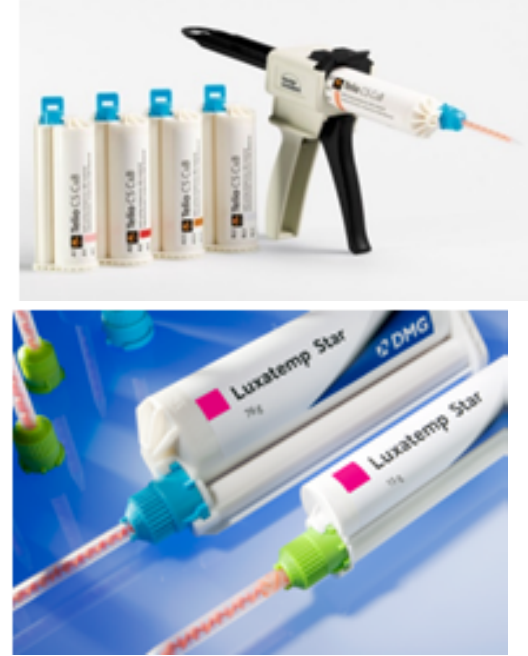

Fig. 2. Luxatemp Star and Telio CS C\&B dimethacrylate resin systems used in the study
The following protocol was used to deliver interim restorations for subjects who requested ceramic veneers:

- evaluation of patients need (comprehensive oral examination, photography, X-rays, study cast). The patient is unsatisfied about shape, colour and alignment of her front teeth (fig. 3a);

- fabrication of a diagnostic mock-up by the laboratory for patient presentation of proposed shape and contour of final ceramic veneers (fig. 3b);

a

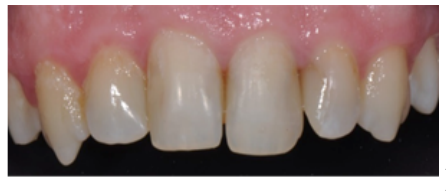

b

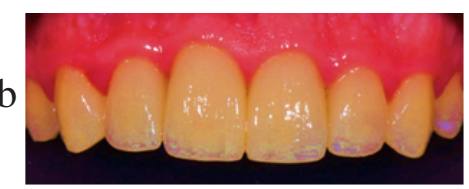

Fig. 3. Pre-operative aspect of maxillary anterior teeth (a); Mock-up made in laboratory (b)

- evaluation of mock-up intraorally in oral cavity for marginal integrity, functionality, occlusion, aesthetics, and patient satisfaction;

- after patient acceptance, a full arch impression with addition silicone was done with mock-up in place and it was use as matrix for temporary restorations. The mockup is used then as a guide for teeth preparation;

- after teeth preparation and impression for final restorations, it was done the direct interim restorations. The silicone impression was shaped on buccal aspect according to cervical aspect of prepared teeth and filled with composite resins and adapted to maxillary anterior tooth preparations with finger pressure until the material was fully polymerized. Excess polymerized acrylic resin was removed with a blade. All contours and embrasures of interim restorations were finished with fine diamonds, ultra-fine diamonds, fluted carbides burs and Sof-lex discs (3M) (fig. 4a);

- the interim veneers were temporarily cemented using acid-etch point technique and bonded with flowable resin composite (fig. 4b). The occlusion was checked and adjusted. The provisional veneers were re-evaluated after a one week following the patient's evaluation of form, function, and aesthetics. If the patient requested modifications, these were performed intraorally and communicated to the dental laboratory. For every patient was allowed four weeks before making final decision.
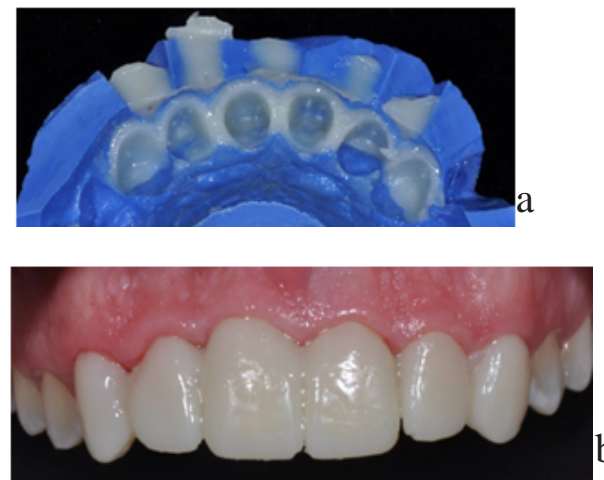

Criteria for interim restorations evaluation are: anatomic configuration, marginal adaptation, loosening, discoloration, surface texture, postoperative pain and periodontal aspect.

- Criterion 1: restoration with anatomical contour and relief in harmony with neighbouring teeth and gingival tissues.

- Criterion 2: continuity between restoration and tooth.

- Criterion 3: absence of loosening.

- Criterion 4: there is no discolouration of temporary crown.

- Criterion 5: restoration has a smooth surface, without fissure or fracture.

- Criterion 6: no postoperative pain or discomfort.

- Criterion 7: no sign of periodontal inflammation.

12 cases were enrolled in this study. All subjects received dimethacrylate resins interim veneers for improving the aspect of upper frontal teeth, before placing final restoration, ceramic veneers. 6 patients received Telio CS (Ivoclar Vivadent) and 6 received Luxatemp Star (DMG). Patients were instructed about maintaining a good oral hygiene and recommended to avoid hard, sticky, chewy, or crunchy foods and also avoid food that contains colour additives.

Patients are evaluated weekly after fixing temporary veneers, during one month. 
Table 1

EVALUATION OF TELIO CS INTERIM VENEERS

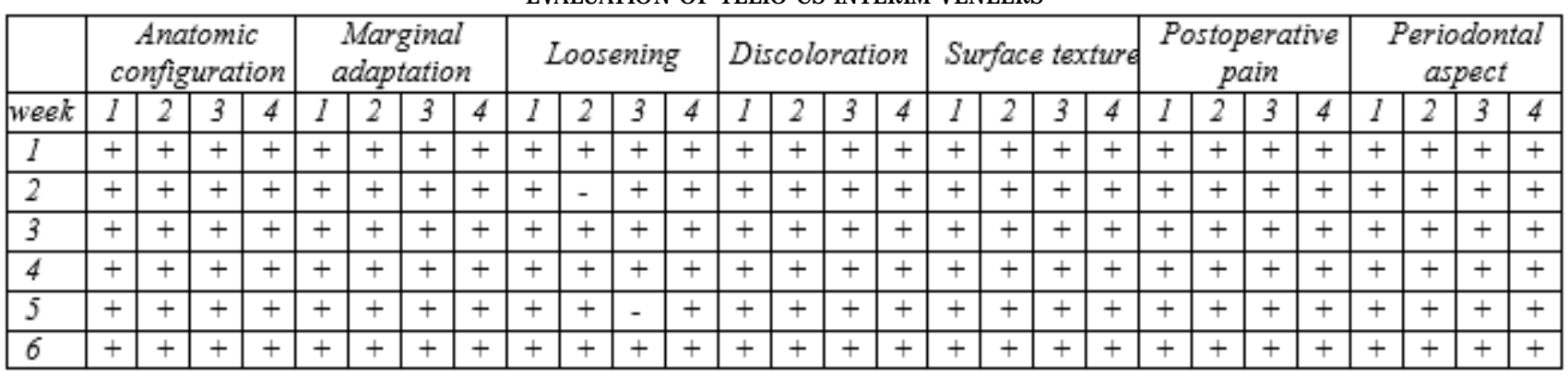

Table 2

EVALUATION OF LUXATEMP STAR INTERIM VENEERS

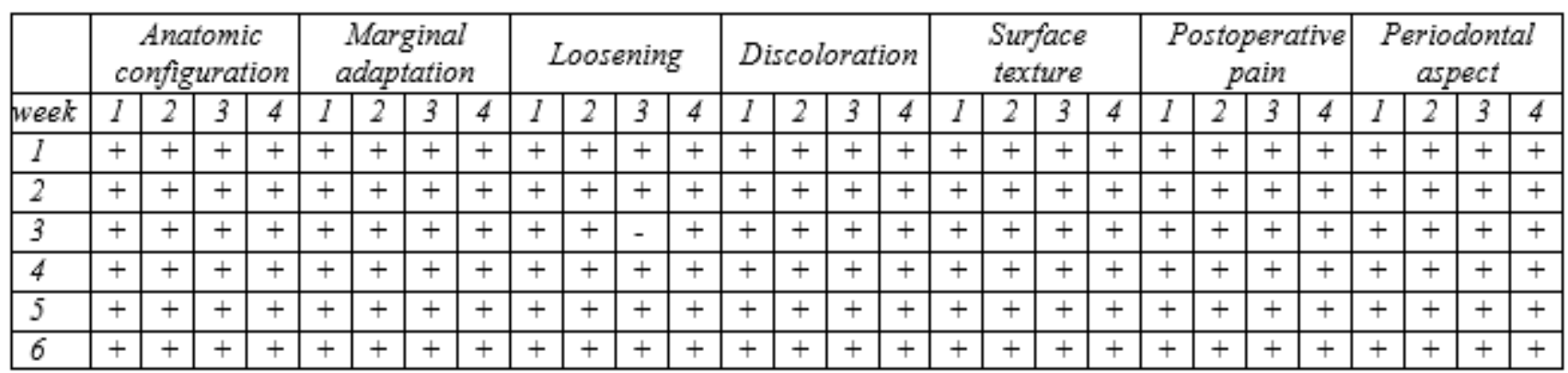

\section{Results and discussions}

Both dimethacrylate based composite resins used in our study performed well, according to evaluation criteria. Loosening of interim restorations appeared in $25 \%$ of cases.

The results of our study are shown in table 1 and table 2.

Dimethacrylate composite resins were chosen as material for interim veneers due to high aesthetic, low shrinkage and low exothermic reaction.

Temporary veneers present some particular aspects in comparison with other temporary restorations. As with any temporary restoration, it is important to be concerned about occlusion and marginal adaptation. Correct gingival marginal adaptation is important with any temporary restoration, but with veneers ithas additional significance. Care should be taken to ensure that there is proper gingival adaptation to avoid tissue irritation leading to gingival recession or bleeding at the cementation appointment. Occlusal loading can easily dislodge temporary veneers, and in time, incorrect distribution of occlusal forces can dislodge or crack the final restoration. In this study dislodgement appeared in 25\% cases. Loosening of the interim veneers is quite common among patients, because veneer do not always have mechanical retention.

Mostly, dimethacrylates are more aesthetic than the methacrylates, but more brittle [3].

Bis-GMA contain composite resins have improved fracture resistance and aesthetics than the methacrylates', allowing their use in anterior applications where aesthetics are essential. Dimethacylates have two active group that produce a relatively cross-link density early on setting reaction, allowing the partially set restoration to be removed without distortion or damage [23].

The composite resins have reduced exothermic reaction during setting and are easier to manipulate [24] and have significant lower polymerization shrinkage than conventional methacrylates [25]. In figure 5 is presented a schematic illustration of methacrylate resin volumetric shrinkage [26].

Current dental composites consist of three essential components: a crosslinked polymer matrix, a high volume fraction of inorganic filler and a coupling agent added to ensure matrix-filler adhesion [27].

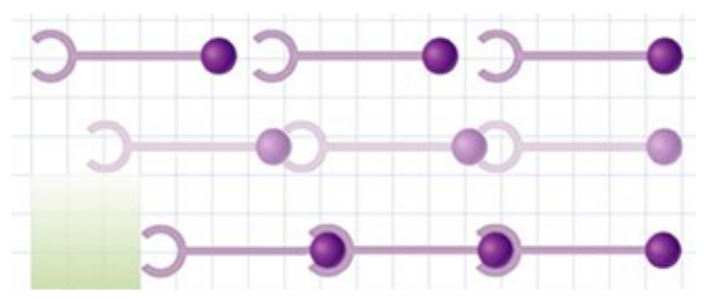

Fig. 5. Schematic illustration of the methacrylate resin volumetric shrinkage

The fractured surface of Bis-GMA-TEGDMA (80:20), on a $20 \mu \mathrm{m}$ scale bar in SEM image is presented in figure 6 [28].

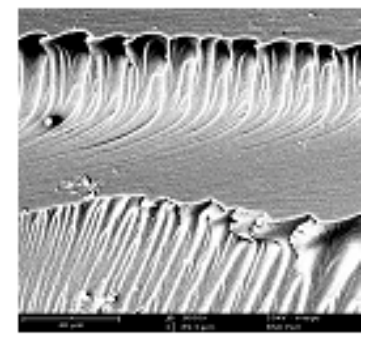

Fig. 6. SEM image of the Bis-GMATEGDMA (80:20) fractured surface (a scale bar $=20 \mu \mathrm{m}$ )

Methacrylates are largely used in medical and dental applications [29], due to a good degree of compatibility with human tissues [30].

Polymers made by methacrylates typically offer good fracture resistance and are easily polished and are easy to repair [31], but have a higher capacity for shrinkage and have less aesthetic appeal than other materials.

Interim material should have low solubility in oral fluids, which ensures a good marginal seal, marginal compressive and tensile strength so that it can withstand moderate occlusal loading and yet be flexible enough to be removed from the tooth surface [32].

Temporary restoratives should demonstrate sufficient mechanical strength to resist the masticatory forces; according to ISO standard for polymer-based crown and bridges materials flexural strength should at least $50 \mathrm{MPa}$ [33]. 
Takamizawa et al [34] showed that Bis-acryl provisional materials demonstrated significantly higher flexural strength than conventional methacrylates. Dimethacrylates are chemically similar to flowable composite resins and as consequence, interim restorations can easily be modified or repaired with more bis-acryl or even flowable composite, but in case of fracture, after repair there is an important decrease in flexural strength [35].

Since one of the major causes for the replacement of provisional restorations is fractures in the body and at the margins [36], it may be more advantageous to make a new provisional restoration than to repair the fractured one for dimethacylates interim.

Biocompatibility is the property of a material to be compatible with living bodies, thus, to be accepted entirely by the body without generating side effects and without being chemically and mechanically deteriorated [37].

A cytotoxicity test (XTT) and an Ames test were carried out with Telio CS C\&B test specimens. In none of the tests was a cytotoxic potential of the material observed. Uncured material may cause a sensitizing reaction due to methacrylates [38].

Nowadays, a wide variety of polymeric materials are available to make satisfactory interim restorations, but the ideal interim material has not been developed yet. A major problem still to be solved is dimensional change during solidification. These materials shrink and cause marginal discrepancy [39-41], especially when the direct technique is used. Another problem is exothermic reaction during curing, and the presence of residual toxic monomer, which makes these materials less biocompatible [42].

\section{Conclusions}

Direct interim veneers made of dimethacrylate composite resins showed good anatomic configuration, good marginal adaptation, no discolorations, no fractures, no postoperative pain and no sign of periodontal inflammation.

The dimethacrylate composite resins permit modification of interim veneers and therefore the final restorations are customised according to patientfeedback.

There are some disadvantages associated with direct interim veneer fabrication: the added cost, increased chair time, and additional appointments for the patient.

Acknowledgements. All authors have equal contribution in preparing the manuscript.

\section{References}

1.ARDELEAN, L., BORTUN, C., MOTOC ,M., RUSU, L.C., Mat. Plast., 47, no. 4, 2010, p. 433

2.BECHIR A, PACURAR M, BECHIR ES, COMANEANU MR, CHIBELEAN CIRES M, MARIS M, BARBU HM, Aesthetic Importance of Resin based Dental Materials used for Orthodontic Appliances, Materiale Plastice, 2014, 51(1), p. 57-61.

3.KURTZMAN GM, STRASSLER HE. Provisional fixed restorations. Dental Economics 2016;3:1-12

4. SINESCU, C, NEGRUTIU, ML, ROMINU, R.O, RUSU, L.C, TOPALA, FI, ROMINU, M., ARDELEAN, L. PODOLEANU, A. Time domain optical coherence tomography evaluation of polymeric fixed partial prostheses. Mat. Plast., 49, no. 1, 2012, p. 58

5.BRAL M. Periodontal Considerations for Provisional Restorations. Provisional Restorations. Dental Clinics of North America. July 1989;457-465

6.ROSENSTIEL SF, LAND MF, FUJIMOTO J. Contemporary fixed prosthodontics. 5th edition. Elsevier Inc. St. Louis 2016; pp.401-54

7.RICE A. Temporization for veneers. Dental Economics 2005;95(3)
8.GARBER DA, GOLDSTEIN RE. Porcelain Laminate Veneers. Chicago, III: Quintessence Pub Co; 1988: pp.11-13

9.BAKEMAN E. Provisional restorations for veneer preparations. Functional Esthetics and Restorative Dentistry 2008;2(2):16-22

10.BECHIR A, BECHIR ES, Biomateriale dentare utilizate in cabinetul stomatologic, Ed. Printech, Bucharest, 2012

11.*** http://www.chimicamo.org/wp-content/uploads/2016/07/ BisGMA.gif

12.NEJ ATIDANESH F, LOTFI HR, SAVABI O. Marginal accuracy of interim restoration fabrication from four interim autopolymerizing resins Journal of Prosthetic Dentistry 2006;95(5):364-367

13.NODITI G, TODEA C. Laser Doppler Imaging - as a Non-invasive Method for Assessing Regional Microcirculation when using Plastic Materials for Guided Healing. Materiale Plastice 2013; 50(1):40-43.

14.*** file:///C:/Users/user4/Downloads/Telio+CS+C\%2526B.pdf

15. *** file:///C:/Users/user4/Downloads/Telio+CS+C\%2526B+\%2528 Base\%2529.pdf

16.*** file:///C:/Users/user4/Downloads/Telio + CS+C\%2526B+ $\% 2528$ Catalyst\%2529.pdf

17.file:///C:/Users/user4/Downloads/Telio+CS+C\%2526B\%20(1).pdf 18.GONCALVES FP, ALVES G, JUNIOR G, OLIVEIRA V, GALLITO MA, OLIVEIRA F, SCELZA MZ. Cytotoxicity Evaluation of Two Bis-Acryl Composite Resins Using Human Gingival Fibroblasts. Brazilian Dental J ournal 2016;27(5):492-496

19.KOCZOROWSKI R, LINKOWSKA-EWIDZIÑSKA K, שFWIDZIÑSKI T, KHMELINSKII I, SIKORSKI M. Color stability of dental temporary composite materials assessed in vitro. In Dental Forum 2016;42(1):1118

20.*** https://www 2.dmg-dental.com/products/temporary-care/ fabrication-of-temporaries/luxatemp/

21.*** http://www.ivoclarvivadent.us/en/telio-cs/telio-cs-candb

22.HASELTON DR, DIAZ-ARNOLD AM, VARGAS MA. Flexural strength of provisional crown and fixed partial denture resins. The Journal of prosthetic dentistry, 2002;87(2), 225-228

23.BONSOR SJ, PEARSON GJ. A Clinical Guide to Applied Dental Materials. Churchill Livingstone. Elsevier Health Sciences, 2013 pp.222227

24.YOUNG HM, SMITH CT, MORTON D. Comparative in vitro evaluation of two provisional restorative materials. The Journal of prosthetic dentistry 2001;85(2):129-132

25. LIBECKI W, ELSAYED A, FREITAG-W OLF S, KERN M. Reducing the effect of polymerization shrinkage of temporary fixed dental prostheses by using different materials and fabrication techniques. Dental Materials 2016;32(12):1464-1471

26.*** http://pocketdentistry.com/9-restorative-materials-compositesand-polymers/

27.BARSZCZEWSKA-RYBAREK I, JURCZYK S, Comparative Study of Structure-Property Relationships in Polymer Networks Based on BisGMA, TEGDMA and Various Urethane-Dimethacrylates, Materials 2015, 8, 1230-1248

28.*** file:///C:/Users/user4/Downloads/materials-08-01230.pdf 29.GOODWIN CJ , BRADEN M, DOW NES S, MARSHALL NJ. Investigation into the release of bioactive recombinant human growth hormone from normal and low-viscosity poly (methylmethacrylate) bone cements. J ournal of biomedical materials research, 1997; 34(1):47-55 30.CIAVOI, G, BECHIR, AM, TIG, I, DALAI, C, MANU, R. Aspects Regarding the use of Three Types of Polymers as Denture Base Material. Mat. Plast., 53, no. 2, 2016, p. 247

31.ABRAMS, S. A technique for veneer temporization. Dentistry today, 2004;23(7):76, 78-9

32.***International Standard ISO 10477. Dentistry - Polymer-based crown and bridges materials. Second edition 01.10.2004

33.TAKAMIZAWA T, BARKMEIER WW, TSUJIMOTO A, SCHEIDEL D, ERICKSON RL, LATTA MA, MIYAZAKI M. Mechanical properties and simulated wear of provisional resin materials. Operative dentistry 2015;40(6):603-613 
34.SINGH A, GARG S. Comparative Evaluation of Flexural Strength of Provisional Crown and Bridge Materials-An Invitro Study. J Clin Diagn Res. 2016 Aug;10(8):72-77

35.J IVANESCU, A., MIHUTESCU, D.H., GOGUTA ,L., PIRVULESCU, L.D., Comparative In Vitro Study of the Flexural Strength of Resin Provisional Fixed Partial Dentures, With and Without Glass Fiber Reinforcement. Mat. Plast., 53, no. 3, 2016, p. 481

36.HANCU, V., COMANEANU, R.M., COMAN, C., FILIPESCU, A.G., GHERGIC, D.L., COTRUT, M.C., In vitro Studies Regarding the Corrosion Resistance of $\mathrm{NiCr}$ and $\mathrm{CoCr}$ Types Dental Alloys, 2014, Rev. Chim.(Bucharest), 65, no.6, 2014, p.706

37.*** file:///C:/Users/user4/Downloads/Telio+CS+C\%2526 B\%20(3). pdf
38.BALKENHOL M, KNAPP M, FERGER P, HEUN U, WÖSTMANN B. Correlation between polymerization shrinkage and marginal fit of temporary crowns. Dental materials 2008;24(11):1575-1584

39.AMIN BM, ARAS MA, CHITRE V. A comparative evaluation of the marginal accuracy of crowns fabricated from four commercially available provisional materials: An in vitro study. Contemporary clinical dentistry 2015;6(2):161-165

40.RAKHSHAN V. Marginal integrity of provisional resin restoration materials: A review of the literature. The Saudi Journal for Dental Research 2015;6(1):33-4

41.ARDELEAN, L, RUSU, L.C, BRATU, D.C, BORTUN, C.M. Diacrylic Composite Resins as Veneering Materials. Mat. Plast., 50, no. 2, 2013, p. 93

Manuscript received: 21.12 .2016 